\title{
STUDIES ON THE NEUROGLIA.
}

\author{
BY \\ G. CARL HUBER, M. D. \\ From the Anatomical Laboratory of the University of Michigan.
}

Our present conception of the structure of neurogliar tissue is based in the main on results obtained by the employment of two fundamentally different methods, each of which is regarded by its supporters as a differential stain for neuroglia. We refer here to the chromesilver method of Golgi, for many years the only method at.our disposal by means of which the structural elements of this tissue could be brought to light. To this method we are indebted for the results obtained by Golgi, v. Lenhossék, v. Kölliker, Ramon y Cajal, Retzius, Sala y Pons, Van Gehuchten, Eurich, Reinke and others in their investigations of the structure and histogenesis of the neuroglia. The other method was the one fully described by Weigert in 1895 in his large monograph on the structure of neurogliar tissue, giving the results of seven years' labor in this field. Almost simultaneously appeared Mallory's publication giving an analogous method. In the Weigert and Mallory methods, the staining is the result of a chemical differentiation of the neuroglia fibers. Their results have been corroborated by Pollack, Krause and Aguerre working with normal tissues and by Taylor, Storch and Bonome in their study of pathological tissue and new growths. Quite recently Benda has published a differential stain for neuroglia, which seems destined to become very useful.

All recent writers on neurogliar tissue have called attention to the apparently contradictory results obtained by those observers working with the chrome-silver method as compared with the recorded observations of investigators who have used the more modern differential stains, and a glance at the more recent literature is sufficient to convince one that a classification of the current views of the structure of neurogliar tissue may with propriety be based on the methods used in the investigation of the tissue. It is, however, not our purpose at the present time to extend this controversy, and a repetition of what has been previously stated in several of the discussions of neuroglia literature seems uncalled for; it will therefore be entered upon only to the extent necessary to present our own observations as clearly and succinctly as possible. 
As is now very generally known, the chrome-silver method shows the neurogliar tissue to consist of cellular elements possessing a varying number of fibrillar processes. These structural elements have been designated by $\mathrm{v}$. Lenhossék by the very appropriate name of astrocytes, and are subdivided into (a) astrocytes with long processes, found in the white and grey matter, and (b) astrocytes with short processes, found only in the grey matter. In these few words we have endeavored to reflect, as well as possible in so short a space, the views of the majority of the early observers who have used the chrome-silver method in the study of neuroglia. V. Kölliker, while agreeing in the main with the above statement of the structure of the neuroglia, describes the fullydeveloped astrocyte, which he terms a Golgi-cell, as consisting of two portions-a cell-body containing the nucleus which is intimately associated with a cell-plate, from which the cell processes arise. He suggests the hypothesis that " a Golgi-cell with a portion of its protoplasm develops a cell-plate from which the cell processes arise; this plate originally and as long as the processes possess the power of growth is intimately connected with the nucleated portion of the Golgi-cell; in many instances, however, the cell-plate attains a different consistency and perhaps also a different constitution and, under certain conditions, may sever its connection with the nucleated portion of the Golgi-cell." Andriezen, who has used the chrome-silver method in studying the neurogliar tissue of the brain cortex, recognizes two varieties of neuroglia cells. One of these, which he has designated as the neuroglia fiber cells, corresponds in the main with the astrocytes with long processes described by other writers. It should, however, be stated that this observer was able to make out in certain of his preparations that not all neuroglia fibers are processes of cells, but that many of them "pass right through the cell body." The other variety of neuroglia cell is described by him under the name of protoplasmic glia cell, and has stout, coarse and very shaggy processes, which vary very greatly in size. These latter cells are said to be of mesoblastic origin. Reinke, who, in his study of neuroglia tissue, has made use of a modified chrome-silver method (after obtaining a chrome-silver precipitate, he dehydrated and then imbedded his tissue in paraffin, fixed the sections with albumin fixative and then stained them with Heidenhain's hematoxylin and counterstained them in eosin), has obtained results which deserve especial mention. His conclusions are "that the neurogliar tissue of the white substance of the human cord consists of (1) cells and (2) fibrils. The cells possess numerous processes, some of which are branched and which run in part transversely and in part obliquely; the majority of 
them, however, run vertically, that is, parallel to the nerve-fibers. These processes are well stained by the chrome-silver method. The fibrils differ morphologically, physically and chemically from the cellprocesses. They are, however, developed from the protoplasm of the cells and lie partly in and partly on the protoplasm and have a direction which in the main is opposite to that of the cell processes. For the most part these fibrils, the length of which is unknown, are emancipated from the cell-bodies. The fibrils differ in thickness and probably do not anastomose. These are the fibrils which are so clearly brought out by the Weigert method."

Erik Müller's "Studies on Neuroglia" may also be mentioned in this connection. His observations were made on tissues taken from amphioxus, myxine, acanthias, and from teleosts; they were fixed by the Golgi method and then stained after Heidenhain's iron-lack-hematoxylin. In all of these forms he finds the neuroglia made up of cells and fibers, which are, however, in such relation to each other that all the fibers may be regarded as processes of cells.

As may be seen from the above brief summary of neuroglia literature giving accounts of observations made with the chrome-silver method, all observers who have used this method, even when such method has been subjected to special modifications, have reached the conclusion that the neuroglia is composed of cellular elements and cell processes-neuroglia-cells and neuroglia-fibers, the latter being the processes of the former. It is true that Andriezen found certain astrocytes in which the neuroglia fibers passed through the cell-body, and that v. Kölliker regards himself justified in describing a cell-plate with cellprocesses, which may under certain conditions become separated from the nucleated portion of the neuroglia cell, and that Reinke believes that he has harmonized the conflicting views by his discovery of two varieties of neuroglia fibers, the one being processes of neuroglia cells and the other developed from the protoplasm and in part at least emancipated from such protoplasm; yet a careful study of the account and figures given by Andriezen and v. Kölliker does not reveal sufficient evidence to indicate that these observers regard the neuroglia fibers as other than processes of the neuroglia cells, and Reinke's statement will need further confirmation with methods other than a chrome-silver precipitate before they can be accepted as established. At this date it does not seem necessary to enter into a consideration of the chromesilver method as such, as its advantages and disadvantages have been the subjects of frequent consideration and are now very generally known; suffice it to say that we agree with Taylor when he states that 
"A method which colors by precipitation is a priori incapable of giving us the information which we require; it must of necessity be confusing in its pictures of structural detail."

We may now turn our attention to the observations of investigators who have employed a differential chemical stain in their study of neuroglia. Weigert, whose comprehensive work gave a new impetus to the study of neuroglia, summarizes his results in the following statements: "The neuroglia fibers, which have been hitherto regarded as processes of Deiters' cells, differ chemically from the protoplasm of these cells. This difference in the chemical constitution of the 'cell-processes' is apparent in the immediate vicinity of the cell nucleus, as well as at some distance from it. The majority of the so-called cell processes are not cell processes since two such apparent processes form a continuous fiber, which is in no way interrupted by the cell body, as would be the case were they true processes arising individually from the cell body. In a word, there is no question here of cell processes or cell extensions, but of fibers which are fully differentiated from the protoplasm." Weigert describes two types of nuclei of neuroglia cells-large, vesicular nuclei the chromatin of which has a granular appearance, and smaller ones in which the chromatin forms a deeply-staining, homogeneous mass, with transition forms between the two varieties. The large vesicular nuclei often show a definite relation to the neuroglia fibers, in that they form centres, over which and around which the neuroglia fibers pass, simulating in a most characteristic manner the astrocytes of other investigators. Numerous free neuroglia cell nuclei, notably of the smaller, deeply-staining variety, which bear no special relation to the neuroglia fibers, are also found.

Mallory, working with his own method, obtained results which were practically identical with those obtained by Weigert. Although these two investigators worked independently, their results were published almost simultaneously. Pollack in a short note confirms Weigert's statements and calls attention to the importance of his differential neuroglia stain and the results obtained. Aguerre, after discussing the recent neuroglia literature and calling attention to the superiority of Weigert's neuroglia stain and corroborating his observations, discusses at some length the shape and structure of the neuroglia cell nuclei as found in the human spinal cord, stating that these nuclei vary much in shape and size and are often polymorphous. He classifies the neuroglia cell nuclei according to their size as follows: (1) small nuclei, $3 \mu$ to $4 \mu$, to which variety the small deeply-stained nuclei belong; (2) medium-sized nuclei, $6 \mu$ to $8 \mu$, the smaller nuclei of the 
vesicular variety; (3) large nuclei of the vesicular variety, often polymorphous and measuring as high as $14 \mu$. Krause and Aguerre, in another communication, describe at some length the distribution of the neuroglia tissue in the human spinal cord. Attention should also be drawn to the fact that these two observers have been able to stain the neuroglia in apes and half-apes, after having slightly modified the Weigert method. Krause has given a full account of the neuroglia in the spinal cord of the ape, in which he describes small, deeply-staining nuclei of neuroglia cells and larger often polymorphous, vesicular nuclei, having only a small amount of chromatin. He finds the majority of the neuroglia fibers fully differentiated and many of them relatively thin. Eurich in his last publication places himself in accord with Weigert's view on the structure of the neuroglia and advances theoretical reasons for accepting the same. It would lead beyond the limits of this paper to do more than mention the observations of Taylor, who worked with the Mallory method, and Storch and Bonome, who used the Weigert method in their study of glioma and gliosis and of the behavior of the neuroglia in certain pathological conditions of the central nervous system of man. As pertains to the structure of the fully-developed neuroglia tissue, their published results confirm in the main the views expressed by Weigert and Mallory and others who have used these methods. Yamagiwa has recently described a new stain for neuroglia which consists of a modification of Ströbe's differential axis-cylinder stain. As a result of observations made with this method, he is led to conclude that the neuroglia fibers are differentiated intercellular structures, which are, however, not entirely or not in all instances completely separated from the neuroglia cells. Mention may also be made of a somewhat crude method described by Whitwell, by means of which he aims to differentiate the neuroglia fibers. Sections from hardened tissues are treated for a few seconds with a hot concentrated solution of caustic potash, are then rinsed in water and allowed to desiccate on the slide. When dry, the sections are covered with a cover glass. In such preparations examined with a moderate magnification, but with good illumination, a dense feltwork of fibrils may be seen. Whitwell regards these fibrils as neuroglia fibers and states that "they show no evidence of being direct processes of cells and do not appear to branch and form a complete basket network for each element in the nervous tissues, including the blood-vessels." Benda has recently described a differential neuroglia stain which will be given fuller consideration presently and will therefore receive no further mention at this time. From the foregoing account it may be seen that those 
observers who have used differential neuroglia stains in their study of this tissue agree in regarding the neuroglia fibers, not as cell processes, since they are readily differentiated from the protoplasm of neuroglia cells, from which they differ in chemical constitution and physical properties, as is shown by these staining methods, but as an intercellular substance emancipated from the protoplasm of the neuroglia cells.

One of the disadvantages of both the Weigert and Mallory neuroglia stains is the fact that these stains can be used only on human tissue; furthermore, owing to the fact that the neuroglia fibers break down very readily, as was pointed out by Virchow many years ago, it is necessary to have at one's disposal very fresh tissue in order to obtain satisfactory staining of the neuroglia. Krause and Aguerre, as has been previously stated, were able by careful manipulation of the Weigert method to obtain successful differential staining of the neuroglia in apes and half-apes; this, however, is the only instance, so far as I have been able to ascertain, in which a successful differential staining of the neuroglia in vertebrates other than man has been obtained. Weigert and Mallory both admit that their neuroglia staining methods are useful only on fresh human tissue. The difficulty of obtaining very fresh human tissue no doubt accounts for the fact that we have so few confirmatory observations of the views of Weigert and Mallory concerning the structure of the neuroglia. The fact that it is often difficult to obtain fresh human tissue and the further fact that these methods cannot be used to stain the neuroglia of animals no doubt explains in part the apparent hesitancy to accept their results in place of the results obtained by the chrome-silver method, by means of which, as is well known, neuroglia tissue may be stained in the central nervous system of all vertebrates, whether embryonic or adult tissue is used. The reason why the Weigert and Mallory stains are selective for human neuroglia only is difficult to explain and must be ascribed to some slight difference in the chemical composition of the neuroglia fibers of man and other vertebrates, in which case we may look upon these staining methods as so highly differential as to be applicable to the staining of human neuroglia only. In the hope that by modifying these methods a procedure might be found by means of which the neuroglia of animals might be stained, I spent much time in experimentation. All of my endeavors, however, proved fruitless so long as I confined my attention to the Weigert and Mallory methods. Much more satisfactory results were, however, obtained after the writer became familiar with the Benda differential neuroglia stain, published in September of last year. Benda was led to continue his endeavors to discover a satisfactory stain for 
neurogliar tissue, partially interrupted by the appearance of Weigert's large monograph, because the Weigert method did not seem to possess the certainty ascribed to it by its discoverer. I am not aware that Benda is familiar with the fact that his method may be used as a differential staining method for the neuroglia of animals. I find, however, no reference to this fact in his account of his method. This fact seems to me, however, of sufficient importance to warrant my giving his method somewhat in detail, since it does away with one of the obstacles to the use of the Weigert or Mallory method-namely, the necessity of using fresh human tissue in order to study the neuroglia with a differential stain.

The method used by me in my study of the neuroglia of animals is essentially the same as the first of the three methods given by Benda. I have not been successful in staining the neuroglia of animals by the other methods given by him.

The method as used by me is as follows:

1. The tissues, which should be in small pieces, not more than $0.5 \mathrm{~cm}$. in thickness, are fixed and hardened for two to four days in a $4 \%$ or $10 \%$ solution of formaldehyde (10 parts or 25 parts respectively of formalin in 100 parts of water). A large quantity of the solution is used and, during the hardening process, the tissues rest on several layers of filter paper placed in the bottom of the dish.

2. The tissues are then placed for two to four days in Weigert's chrom-alum mordant, used in his neuroglia stain, the solution being kept in the warm oven at $38^{\circ} \mathrm{C}$. during this step.

3. Wash in flowing water for 24 hours.

4. Place tissues for two to four days in a $0.5 \%$ aqueous solution of chromic acid.

5. Wash for 24 hours in flowing water.

6. Dehydrate in graded alcohol. It is necessary to dehydrate the tissues very thoroughly.

7. Imbed in paraffin. It is necessary that this procedure be very carefully carried out. After dehydration the tissues are placed in xylol for 24 hours, renewing the xylol several times; then place them for 12 hours in toluol and again 12 hours in benzole. Renew the benzole and add an equal quantity of melted soft paraffin and place in the warm oven. At the end of 24 hours the mixture of benzole and paraffin is replaced by soft paraffin and in three to four hours by hard paraffin ( $58^{\circ} \mathrm{C}$. melting point, Grübler); after three hours' stay in this, they may be imbedded. 
8. Cut sections and fix to slide or cover glass with albumin fixative. To facilitate the application of this step, I may say that sections from paraffin-imbedded tissues of the central nervous system are most readily made by placing the knife at an angle of about $30^{\circ}$ and placing a layer of distilled water on the knife, renewing it constantly as necessity requires. I have found no difficulty in cutting $3 \mu$ to $5 \mu$ sections of the spinal cord or even of the medulla of animals ordinarily used in the laboratories. The sections are then caught on a small brush and floated on distilled water contained in a small evaporating dish. When 40 to 50 sections have been cut and floated on the distilled water, the evaporating dish is placed over a flame and the water is gently heated until the sections flatten out, care being taken not to melt the paraffin. The sections are then caught on cover glasses smeared with a thin layer of albumin fixative and placed for 24 hours in the warm oven.

9. Remove paraffin and bring sections through alcohol into distilled water.

10. The sections are now placed for 24 hours in a mordant consisting either of a $4 \%$ solution of ferric alum or of a solution of liquor ferri tersulphatis, made by adding one part of this to two parts of distilled water.

11. Sections are rinsed in two tap waters and one distilled water and placed for 24 hours in a solution of sodium sulphalizarate, made by adding to distilled water a sufficient quantity of a saturated solution of sodium sulphalizarate in $70 \%$ alcohol to give the distilled water a sulphur-yellow color.

12. Rinse the sections in distilled water and dry between filter papers.

13. Sections are now stained for 15 minutes or longer in a $0.1 \%$ solution of toluidin blue, which should be heated, after the sections are in the stain, until the solution steams. Allow the stain to cool and rinse sections in distilled water.

The sections are next rinsed in a slightly-acidulated solution. For this purpose Benda recommends primarily a 1\% aqueous solution of glacial acetic acid, in which the sections remain for five to ten seconds and are then dried between filter papers, hastily washed in absolute alcohol and placed in creosote. This step was found necessary in staining the neuroglia of the frog, tortoise and dove. Benda further recommends the use of acidulated alcohol, made by me by adding six drops of hydrochloric acid to $100 \mathrm{ccm}$. of $70 \%$ alcohol. This was found more useful in differentiating the neuroglia of mammalia (dog, cat, rabbit), and experience showed that the proper degree of washing was usually 
attained by dipping the sections into this solution as many times as there were micra in the thickness of the section. Tne further procedure is as above.

15. The sections are differentiated in creosote. Benda states that the sections are properly differentiated after they have remained in the creosote about ten minutes. In my work, however, the time varied from about ten minutes to several hours. Sections washed in acidulated alcohol are usually differentiated in about ten minutes; sections washed in the dilute acetic acid solution require a much longer time, varying from one to several hours. It is therefore necessary at all times to control the differentiation under the microscope.

16. After differentiation in the creosote the sections are dried between filter papers, washed in several xylols and mounted in xylolbalsam.

To the naked eye, preparations well differentiated should have a bluish-red or brownish-red color, large masses of neuroglia showing as blue areas. Under the microscope, the neuroglia fibers appear stained deeply blue and stand out very distinctly. The chromatin of the neuroglia cell nuclei presents a purplish-blue color; the remainder of the nucleus is brownish-red and the protoplasm is of the same color, but of a lighter hue. The myelin and neuraxes of the nerve fibers are of a brick-red or brownish-red color, the neuraxes staining much more deeply than the myelin. The nerve cells are of a brownish-red color, the chromophile substance staining more deeply, and the nucleoli are a deep purplish-blue. The fibrous connective tissue stains a pink-red, its nuclei a purplish-blue. The red-blood cells are of a dark greenishblue. The colors here given are those seen in a well-differentiated preparation, especially after washing in acidulated alcohol (step 14). In case the acetic acid wash is used, the myelin and neuraxes retain some of the blue color, giving them a reddish-purple or even a bluish tinge, the axis-cylinders staining more deeply; even in such preparations, however, the neuroglia fibers may be clearly made out by reason of their deep blue color. It is necessary to add that it is not always possible to obtain a clear differentiation, as the method while often reliable, is not without its whims. It is my custom to fix as many sections to one cover glass as I can, and nearly always some of the sections, if not all, will show the desired result. In over-differentiated preparations, the neuroglia fibers have a brownish-red color, but may usually be clearly seen. Such preparations may, after removal of the creosote and xylol, be brought into water and then stained again in toluidin blue, the further treatment being as above described. 
For this investigation material was obtained from the following vertebrates:

Mammalia-Dog, cat, rabbit.

Birds-Dove.

Reptilia-Tortoise (Emys meleagris).

Amphibia-Frog (Rana Catesbiana and Rana halecina).

It is my purpose at this time to give a brief descriptive statement of observations made on the neuroglia of the spinal cord of the abovementioned vertebrates, differentially stained after Benda's method; I shall deal only with the structure of the neuroglia tissue of adult animals and not with its origin nor its distribution. A much more extended treatment of this subject is contemplated and many of the statements here made will then be substantiated by figures. This will appear on the completion of work now in progress.

Dog. In the dog, the neuroglia of the spinal cord consists of neuroglia cells and neuroglia fibers. With the method used, the nuclei of the neuroglia cells stain a purplish-blue color the protoplasm a brownish-red and the neuroglia fibers a deep blue. The nuclei of the neuroglia cells vary greatly in shape and structure, but may be described under two general types with transition forms. The majority of the neuroglia cell nuclei are vesicular with the chromatin arranged in fine granules. The nuclei belonging to this type vary greatly in shape and size. In the smaller varieties, which are generally of round or oval shape, the chromatin is in the form of numerous small granules; in the larger varieties, which are round, oval, or polymorphous, the chromatin is found in the form of one or several granules, the nucleus being otherwise homogeneous in appearance. The nuclei of the other type, which are not numerous, stain diffusely and usually quite deeply and are usually of round or oval shape and generally quite small. The Benda method has the advantage of staining the protoplasm of the neuroglia cells. The amount of protoplasm seen in connection with the different neuroglia nuclei varies greatly. In connection with the small vesicular nuclei with numerous chromatin granules, it is often difficult to make out any protoplasm, many of them appearing as free nuclei; now and then, however, a thin layer of protoplasm is made out, either surrounding the whole nucleus or appearing at only one side of it. The large vesicular nuclei with one or several larger chromatin granules are usually associated with larger masses of protoplasm, in which case distinct neuroglia cells are distinguished. In cross sections of the spinal cord, such cells present a variety of appearances, their shape depending more or less on the space occupied; they may be triangular or quadran- 
gular or somewhat spindle-shaped, with a varying number of processes (usually not more than four or five), which may be traced for short distances between the nerve fibers; such processes are, however, not always made out and when present give the cell a very characteristic appearance. These cells are easily recognized in longitudinal sections of the spinal cord by reason of the structure of their nuclei. The cell protoplasm is often clearly brought out, the cells presenting a rectangular or irregularly oval shape with now and then a few short processes. The small, round or oval deeply-staining nuclei are often associated with a small amount of protoplasm, which usually stains somewhat deeply, often making it difficult to distinguish between protoplasm and nucleus.

The neuroglia fibers stain deeply blue. They vary somewhat in size, but the majority are relatively fine and only here and there does one find coarser fibers. The relation of the neuroglia fibers to the neuroglia cells or free nuclei is generally easily ascertained, in both cross and longitudinal sections of the cord. In the majority of instances, the neuroglia fibers are seen passing over or under the neuroglia cells or nuclei and appear independent of them. Other fibers are seen, however, in close proximity to cells and are seen to lie against them. The large neuroglia cells with protoplasmic branches are particularly interesting in this connection. In such cells it is often possible to trace one or several neuroglia fibers along the side of a protoplasmic branch to the cell body and then either directly across the cell and away from it, or along the side of some other protoplasmic branch and then away from the cell. Three, four or more neuroglia fibers may thus be traced over or under or along the borders of one of these branched neuroglia cells. Usually also numerous small blue dots, cross sections of neuroglia fibers, are seen in close proximity to such cells and now and then in the peripheral portion of their protoplasm; this latter fact must be interpreted as showing that some of the neuroglia fibers pass through the protoplasm of the neuroglia cells. Longitudinal sections of the cord give a better idea of the course of the neuroglia fibers than can be gained from cross sections. In longitudinal sections it will be seen that the neuroglia fibers run parallel to the nerve fibers, at right angles to them and obliquely across them. The relation of the neuroglia fibers to the deeply-staining cells above mentioned is often more difficult to make out, since the cell protoplasm of such cells and the neuroglia fibers now and then stain more nearly the same color than is the case with other cells. In such cells, the neuroglia fibers often appear as processes of the cells, especially when a cross section is studied 
and when a section is not completely differentiated. In well-differentiated sections and more easily in longitudinal sections, it may usually be made out very clearly that the neuroglia fibers pass over or under or in close proximity to such cells and are not interrupted by them.

Cat.-The neuroglia of the spinal cord of the cat presents essentially the same appearances as those described for the dog. Nearly all of the neuroglia cell nuclei are of the vesicular variety with very little chromatin. In many of the cells, very little protoplasm can be made out, the nuclei appearing as free nuclei. In others, the protoplasm, staining a brownish red color, is readily made out, such cells often appearing distinctly branched, with three, four or five protoplasmic branches, varying in thickness and length and recognized between the cross-cut nerve fibers. The neuroglia fibers of the spinal cord of the cat are somewhat coarser than those found in the dog. They are clearly differentiated and may be traced over or under or around the neuroglia cell nuclei or neuroglia cells. The statements made concerning the relation of the neuroglia cells and nuclei and neuroglia fibers, as seen in the dog, are equally applicable for the cat and need, therefore, no further repetition.

Rabbit.-The neurogliar tissue of the spinal cord of the rabbit is not so easily stained differentially as that of the dog and cat. This is due to the fact that the protoplasm of many of the neuroglia cells shows a greater affinity for the toluidin blue than seems to be the case in the dog and cat and, as a consequence, one often finds neuroglia cells with protoplasm and nucleus staining a purplish color, sometimes of a lighter and sometimes of a darker shade. A longer differentiation in the creosote bleaches not only such cells but also to some extent the neuroglia fibers. The right degree of differentiation is therefore somewhat diffcult to obtain. The majority of the nuclei of the neuroglia cells are of the vesicular type, varying greatly in size and shape and in the character and amount of chromatin contained. This may be present in the form of numerous fine granules or as one or several larger granules. Small nuclei, staining deeply, are found, but are not numerous. Many of the nuclei appear as free nuclei and show no or very little protoplasm surrounding them. The large vesicular nuclei, with one or several granules, are generally found in masses of protoplasm which are readily made out. Such cells are usually branched and when stained are purplish-blue in color; the protoplasmic branches can be very readily traced between the nerve fibers. The neuroglia fibers of the rabbit are relatively fine and stain a deep blue color and, in the great majority of cases, it can be readily seen that the fibers are independent of the nu- 
clei and protoplasm of the neuroglia cells. In case of the branched neuroglia cells, when the protoplasm is stained a purplish-blue, it is now and then difficult and in certain cells quite impossible, in cross sections of the cord, to differentiate between neuroglia fibers and protoplasmic branches of neuroglia cells. It is often possible to trace with the utmost clearness a neuroglia fiber along the side of a protoplasmic branch of a neuroglia cell, along the side of or over the cell and by the side of some other protoplasmic branch and away from the cell. At other times, however, when a neuroglia fiber appears cut near the cell body of a neuroglia cell or near one of its protoplasmic branches, it appears as if the neuroglia fiber terminated in the cell. In longitudinal sections of the spinal cord of the rabbit, the relation of the neuroglia fibers to the cells under discussion is more readily made out. In such sections, the neuroglia fibers can be readily traced over, under, and around the neuroglia cells, even though at times the color of the neuroglia fibers is similar to that of the protoplasm of the cells.

Dove.-I have had more difficulty in staining the neuroglia of the spinal cord of birds than was experienced with the other vertebrates studied. This is due to the fact that with the method used the neuroglia fibers seem to bleach out at about the same time as the neuroglia cells and nerve fibers. When well stained, the color of the neuroglia fibers is a light blue and, even in the most successful preparations, they do not stand out as clearly as in the mammalia studied. In cross sections of the cord, the great majority of the neuroglia cells of the white matter appear as branched cells with relatively large vesicular nuclei, containing numerous chromatin granules. The protoplasm of such cells often stains a reddish-blue or purplish-blue color. Here and there in the white matter and more generally in the grey matter, free neuroglia cell nuclei are seen of vesicular structure and containing numerous chromatin granules, or similar nuclei surrounded by very little protoplasm.

The neuroglia fibers in the spinal cord of the dove are relatively fine. In longitudinal sections, it can be seen that they are independent of the cell protoplasm of the neuroglia cells; in cross sections of the cord, it is more difficult to see this, but in favorable sections, one can usually trace the neuroglia fibers over or along the borders of the neuroglia cells and gain the conviction that they are not the processes of these cells.

Tortoise.-The neurogliar tissue of the spinal cord of reptilia is quite easily stained by the Benda method, the neuroglia nuclei and cells staining a brownish-red and the neuroglia fibers a deep blue. The nuclei of 
the neuroglia cells are generally vesicular and show usually only one round or oval refractive granule, which stains deeply and of a purple color. The amount of protoplasm found with these nuclei varies and oftentimes is scarcely made out. Protoplasmic branches, when present, are slender and short. Here and there are found nuclei, which stain reddish-blue with protoplasm of the same color; such cells usually present clearly-marked protoplasmic branches. The neuroglia fibers vary much in thickness, stain a deep blue and are readily differentiated from the protoplasm of the neuroglia cells and may be traced over and along the borders of the neuroglia cells, often following the protoplasmic branches when these are present.

Frog.-In the frog, the greater proportion of the nuclei of the neuroglia cells are large, round, oval, or polymorphous and vesicular in structure. They are often stained a purplish-blne color, in which case they present a homogeneous appearance; when more bleached, they show numerous small chromatin granules. Here and there, smaller nuclei, staining deeply are also found and are more clearly seen in longitudinal sections. Many free nuclei or nuclei with very little protoplasm are found. The amount of protoplasm found varies greatly with the different cells. The protoplasm usually stains a reddish-blue or purplish-blue color. Branched neuroglia cells are found in the white matter of the cord.

The neuroglia fibers of the spinal cord of the frog are relatively very large and are stained a deep blue color. The greater proportion of these fibers run at right angles to the nerve fibers and in cross sections may often be traced for relatively long distances. In cross sections, not many fibers-usually not more than three or four-are seen in relation with any one neuroglia cell or nucleus. The relation of the neuroglia fibers to free nuclei and neuroglia cells is generally very clearly made out; the neuroglia fibers being so large and of such definite course, we are enabled in both longitudinal and cross sections to differentiate between these fibers and other structures. The neuroglia fibers can usually be traced over or by the side of neuroglia cell nuclei or neuroglia cells and are in no way interrupted by the protoplasm of such cells.

\section{Conclusions,}

These observations seem to warrant the following conclusions:

1. The neuroglia of the spinal cord of the dog, cat, rabbit, dove, tortoise and frog consists of neuroglia fibers and neuroglia cells. The neuroglia fibers differ chemically from the protoplasm of the neuroglia 
cells-as shown by differential staining-but this difference is not equally well marked in all the forms studied. In the animals studied, this chemical difference between the protoplasm of neuroglia cells and neuroglia fibers is most marked in the dog, cat and tortoise, less so in the rabbit and frog and least in the dove.

II. The neuroglia fibers may be regarded as intercellular structures, as they bear no constant relation to the great majority of the cell nuclei or neuroglia cells observed.

III. By reason of the fact that the protoplasm of the neuroglia cells is stained by the Benda method, this method has been helpful in showing that there are certain neuroglia cells, usually possessing protoplasmic branches, the neuroglia fibers of which are not completely separated from the protoplasm, but are in continuity with it or even pass through it. That such neuroglia fibers are not simply processes of the cells is usually clearly shown by their chemical reaction-behavior toward stains-and by the fact that such fibers may generally be traced over, under, or along the sides of such cells without suffering interruption. That such cells are normal constituents of neurogliar tissue is shown by the fact that they occur in the spinal cord of the four classes of vertebrates studied.

IV. These observations present no evidence which would go to confirm v. Kölliker's hypothesis concerning the structure of neuroglia cells -namely a nucleated cell body with differentiated cell-plate, from which arise processes, the neuroglia fibers. Cross and longitudinal sections of the spinal cord of the animals studied show no such relation of neuroglia fibers and neuroglia cells. These observations cannot be used in confirmation of Reinke's views of the structure of the neuroglia. The branched neuroglia cells seen by me bear no resemblance to the astrocytes or astroblasts, as seen in the chrome-silver preparations with which I am familiar, nor do they resemble the figures given by Reinke. In my own preparations, the neuroglia fibers very generally follow the course of the protoplasmic branches of the neuroglia cells.

V. The observations here presented strengthen materially the position held by Weigert and Mallory as to the structure of neuroglia tissue, as well as by others who may have used their methods or modifications thereof in the study of neuroglia, and extend their observations to cover the more important vertebrate classes.

Finally the following quotation from Pollack's article may serve to emphasize the further advantages of the method used by me: "Angesichts des Umstandes aber, dass wir des Thierexperimentes nicht entrathen können, da wir ja am Menschen keine Versuche mit experi- 
menteller Degeneration anstellen können, erscheint mir die Anwendbarkeit auf das thierische Nervensystem als das nächste Postulate dieser hochbedeutsamen Methode." This postulate, it seems to me, has to a large extent been met by the introduction of the Benda differential neuroglia stain. I may add that experimental work on cats and dogs, undertaken with a view of studying the behavior of the neuroglia under certain pathologic conditions has been begun and will form the subject of some future contribution.

In conclusion I wish to thank Mr. August Henry Roth, student in medicine, for much valuable assistance given in the preparation of the sections on which these observations are founded.

\section{REFERENCES TO LITERATURE.}

1900. J. A. Aguerre.-Untersuchungen über die menschliche Neuroglia. Archiv f. Mik. Anatom. und Entwicklungsgesch., Vol. LVI, p. 509.

1893. W. LLOYd ANDRIEZEN.-The Neuroglia Elements in the Human Brain. Brit. Med. Journ., Vol. II, July-Dec., p. 227.

1900. C. BENDA.--Erfahrungen über Neurogliafärbungen und eine neue Färbungsmethode. Neurologisches Centralblatt, Vol. XIX, p. 786.

1901. A. Bonome.-Bat und Histogenese des pathologischen NeurogliaGewebes. Virchow's Archiv, Vol. CLXIII, p. 441.

1897. F. W. Eurich.-Studies on the Neuroglia. Brain, Vol. XX, p. 114.

1898. F. W. EURICH.-Contribution to the Comparative Anatomy of the Neuroglia. Journal of Anatomy and Physiology, Vol. XXXII, p. 688 .

1899. R. KRAUSE.--Untersuchungen über die Neuroglia des Affen. Anhang z. d. Abh. der Königl. Akad. der Wissenschaften zu Berlin. 1899.

1900. R. Krause and J. AguerRe.-Untersuchungen über den Bau des menschlichen Rückenmarkes mit besonderer Berücksichtigung der Neuroglia. Anat. Anzeiger, Vol. XVIII, p. 239.

1893. A. v. KöLLJKEn.-Handbuch der Gewebelehre des Menschen, 6 Aufl., Vol. II, pp. 136 to 193.

1895. F. B. Mallony.-Centralblatt f. Allg. Pathol. u. path. Anat., Vol. VI, p. 753; also Method of Fixation for Neuroglia Fibers, pp. 532-3, Journal of Exp. Med., Vol. II, 1897.

1899. ErIK MÜLIER.-Studien über Neuroglia. Arch. f. Mik. Anatom. und Entwicklungsgesch., Vol. LV, p. 11.

1897. B. Pollack.-Einige Bemerkungen über die Neuroglia und Neurogliafärbung. Arch. f. Mik. Anatom. und Entwicklungsgesch., Vol. XLVIII, p. 274 .

1897. Fr. Rernke.-Ueber die Neuroglia in der weissen Substanz des Rückensmarks vom erwachsenen Menschen. Arch. f. Mik. Anatom. und Entwicklungsgesch., Vol. L, p. 1. 
1899. E. Sтовсн.-Ueber die pathologish-anatomischen Vorgänge am Stützgerüst des Centralnervensystems. Virchow's Archiv, Vol. CLVII, p. 127.

189\%. E. W. TAYLOR.-A Contribution to the Study of Human Neuroglia. The Journal of Experimental Medicine, Vol. II, p. 611.

1895. C. WejgerT.-Beiträge zur Kenntniss der normalen menschlichen Neuroglia. Festschrift, Frankfurt a M.

1898. J. R. Whrtwell. - On the Structure of the Neuroglia. British Med. Journ., Vol. I, Jan.-June, p. 681.

1900. K. Yamagrwa.-Eine neue Färbung der Neuroglia. Virchow's Archiv, Vol. CLX, p. 358. 